\title{
Infection of Cranberry Flowers by Monilinia oxycocci and Evaluation of Cultivars for Resistance to Cottonball
}

\author{
P. S. McManus, V. M. Best, and R. P. Voland
}

Department of Plant Pathology, University of Wisconsin, Madison 53706.

Accepted for publication 20 August 1999.

\begin{abstract}
McManus, P. S., Best, V. M., and Voland, R. P. 1999. Infection of cranberry flowers by Monilinia oxycocci and evaluation of cultivars for resistance to cottonball. Phytopathology 89:1127-1130.

Infection of cranberry flowers by conidia of Monilinia oxycocci, the cottonball pathogen, was investigated using a squash-mount histological method. Conidia germinated on anthers, nectaries, petals, and stigmata, but not styles. The stigma was the only flower part penetrated by the fungus, but no specialized infection structures were noted. Both fungal and pollen germ tubes grew through the stylar canal and made contact

Cottonball incidence was greatest when stigmata were inoculated; the low level of cottonball that resulted from inoculation of other flower parts and in noninoculated flowers was attributed to contamination of stigmata. In greenhouse tests, cottonball incidence was $25,28,31$, and $38 \%$ for cvs. Searles, Pilgrim, Ben Lear, and Stevens, respectively, and was greater for $M$. oxycocci isolate 593 than isolate 591. We conclude that the stigma is the sole floral infection court for conidia of $M$. oxycocci and that the most popular cranberry cultivars in Wisconsin do not differ in inherent resistance to cottonball. The relevance of these findings to the long-term management of cottonball is discussed.
\end{abstract} with ovules and nucellar tissue by $72 \mathrm{~h}$ after inoculation and pollination.
Cranberry (Vaccinium macrocarpon Aiton) is the most important fruit crop in Wisconsin, with $\approx 5,600$ ha in production and a farm gate value estimated at $\$ 120$ million. Wisconsin led the United States in cranberry production in 1995 to 1998 and is expected to maintain its status as the top producer because $\approx 200$ to 400 ha of new plantings are established annually. Cottonball, caused by the fungus Monilinia oxycocci (Woronin) Honey, is the most serious disease affecting cranberry in Wisconsin. Left unchecked, disease incidence can exceed $40 \%$ (7). Infected fruit are unfit for fresh or processing markets, and fruit-receiving stations assess growers sorting fees if cottonball incidence is high in shipments.

M. oxycocci overwinters as pseudosclerotia beneath the dense cranberry canopy. In the spring, apothecia emerge from pseudosclerotia and release ascospores during the time that shoots elongate. Primary infection occurs when ascospores land on newly elongating, succulent shoots. At $\approx 3$ to 4 weeks after primary infection, coinciding with bloom, conidia are borne on ectostromata on the infected shoots. Conidia are carried by wind, insects, or both to flowers, whereupon secondary infection occurs. The sole floral infection court for $M$. oxycocci is presumed to be the stigma, as is the case for $M$. vaccinii-corymbosi, the mummy berry pathogen of blueberry $(1,12,14)$, although this has not been determined experimentally. As fruit mature, the fungus fills the locules with white, cotton-like mycelia. Secondary infection leads to economic losses, and field research suggests that control is more efficient when this stage of the disease cycle is targeted $(7,11)$.

Approximately 20 to $25 \%$ of the cranberry crop in Wisconsin is treated annually with up to four applications of propiconazole, a sterol demethylation inhibitor (DMI) fungicide, specifically for control of cottonball. However, reliance on fungicides is unsound because of risks associated with environmental and human health and the evolution of fungicide-resistant populations of the pathogen (11). Although cottonball occurs to some extent on all of the

Corresponding author: P. S. McManus; E-mail address: psm@ plantpath.wisc.edu

Publication no. P-1999-1012-01R

(c) 1999 The American Phytopathological Society popular cultivars of cranberry in Wisconsin, the relative resistance of cranberry cultivars has not been determined, and anecdotal reports on cultivar resistance have been inconsistent (8). Cranberry is a long-lived perennial crop capable of yielding well for several decades, and the cost of establishing a planting is $\$ 75,000$ to $100,000 /$ ha; therefore, choosing suitable cultivars is essential. Also, use of cultivars relatively resistant to cottonball would reduce the population of $M$. oxycocci exposed to fungicides and thereby reduce overall selection for fungicide resistance.

The study reported here contributes to our greater effort to develop a sustainable, integrated program for controlling cottonball $(9,11)$. The objectives were (i) to identify the specific floral infection court or courts of $M$. oxycocci and determine the presence or absence of infection structures and (ii) to screen cultivars of cranberry for resistance to floral infection by $M$. oxycocci.

\section{MATERIALS AND METHODS}

Collection and maintenance of cranberry plants. Dormant cranberry plants (cvs. Ben Lear, Pilgrim, Searles, and Stevens) were dug from commercial plantings in central Wisconsin during November 1997 and transplanted into a mixture of peat and sand (3:1, vol/vol). To minimize the influence of genetic variability within cultivars (13), all plants of a given cultivar were collected from a single cranberry bed. Plants were vernalized in an unheated greenhouse for 15 to 20 weeks with occasional watering. During March 1998 , plants were transferred to a greenhouse at $\approx 25^{\circ} \mathrm{C}$ with a $16-\mathrm{h}$ photoperiod. Additional plants were collected and transplanted during late April 1998, just before shoot growth resumed. Some plants were placed in a greenhouse; others were held dormant at $4^{\circ} \mathrm{C}$ in darkness for $\approx 5$ weeks and subsequently transferred to a greenhouse. The purpose of these treatments was to stagger plant development and ensure that flowers would be available over several weeks.

Fungal inoculum. $M$. oxycocci was isolated from surface-disinfested symptomatic cranberry shoots and fruit on potato dextrose agar (PDA) amended with streptomycin sulfate at $100 \mu \mathrm{g} \mathrm{ml}^{-1}$ to inhibit bacterial growth. Although conidia germinated on water 
agar and PDA, colonies never developed from individual conidia, and obtaining single-conidial isolates was not possible. Therefore, in this study, an isolate was defined as the fungal mycelium that grew from a single infected shoot or fruit and the asexual progeny of that mycelium. Isolate 591 originated from an infected shoot of a native cranberry selection on a commercial marsh in Jackson County, WI, and isolate 593 originated from an infected shoot of cv. Ben Lear on a commercial marsh in Monroe County, WI. Isolates were stored as mycelia and spores in sterile water at $4^{\circ} \mathrm{C}$. Cultures were removed from storage and incubated at $20^{\circ} \mathrm{C}$ with a 12 -h photoperiod provided by fluorescent lights; conidia were produced after 7 to 14 days. Plugs $\left(\approx 1 \mathrm{~cm}^{2}\right)$ of agar covered with sporulating hyphae were used for inoculating flower parts.

Infection court studies. Inoculation of flower parts. Agar plugs covered with sporulating hyphae were rubbed against flower parts including anthers, nectaries, petals, stigmata, and styles of cvs. Ben Lear and Pilgrim. Flowers were emasculated prior to inoculation of nectaries or styles. To ensure a high rate of fruit set, stigmata were hand-pollinated at the same time the inoculum was applied and 24 to $36 \mathrm{~h}$ later. Control flowers were pollinated but not inoculated. At least 40 flowers of each cultivar were used for each flower-part treatment (trial 1). For each treatment, 6 to 15 flowers were examined microscopically; remaining flowers were allowed to develop into fruit. The experiment was repeated 1 year later on a larger scale (trial 2), using $\approx 100$ flowers of each cultivar for each flower-part treatment. Various isolates were used in the two trials, but inoculations with any given isolate were distributed approximately equally among the different flower parts and between the two cultivars.

Histology and microscopy. Flower parts were harvested and fixed in Histochoice (Amresco, Solon, $\mathrm{OH}$ ) at 48 and $72 \mathrm{~h}$ after inoculation. Samples were hydrolyzed in $\mathrm{KOH}(10 \% \mathrm{wt} / \mathrm{vol})$ at $60^{\circ} \mathrm{C}$ for $10 \mathrm{~min}$, stained, and mounted in decolorized aniline blue dissolved in $0.15 \mathrm{M} \mathrm{K}_{2} \mathrm{HPO} 4, \mathrm{pH} 12(0.1 \% \mathrm{wt} / \mathrm{vol})$. Flower parts were flattened by squashing under a coverslip and observed with a $\mathrm{BH} 2$ epifluorescent microscope (Olympus Corporation, NY) equipped with DAPI (4',6-diamidino-2-phenylindole) filters.

Cultivar screening. The four most popular cranberry cultivars in Wisconsin (Ben Lear, Pilgrim, Searles and Stevens) were screened for susceptibility to floral infection by $M$. oxycocci isolates 591 and 593. The experimental design was a randomized complete block with five blocks. A block consisted of 18 to 35 flowers of each cultivar inoculated with isolate 591 or 593. For controls, five groups of 10 to 30 flowers of each cultivar were pollinated but not inoculated and then randomized among the inoculated plants. All flowers were pollinated and inoculated a second time 20 to $30 \mathrm{~h}$ after the first pollination and inoculation. The entire experiment was repeated once, except that no flowers of cv. Ben Lear were available for the second experiment.

Disease rating and data analysis. Flowers not used for microscopic analysis were allowed to develop for $\approx 30$ days, after which cottonball incidence was determined by cutting fruit transversely and observing the presence or absence of white mycelia in the locules. Cottonball incidence was defined as the number of infected berries per total number of berries multiplied by 100. All statistical calculations were performed using SAS software (version 7, SAS Institute Inc., Cary, NC.). Trials 1 and 2 of the flower-part inoculation experiment were analyzed separately, with each cranberry flower considered as an experimental unit. When the flower did not produce a mature fruit, disease incidence was recorded as a missing value. Data were analyzed as contingency tables using PROC FREQ; proportions were compared using Fisher's exact
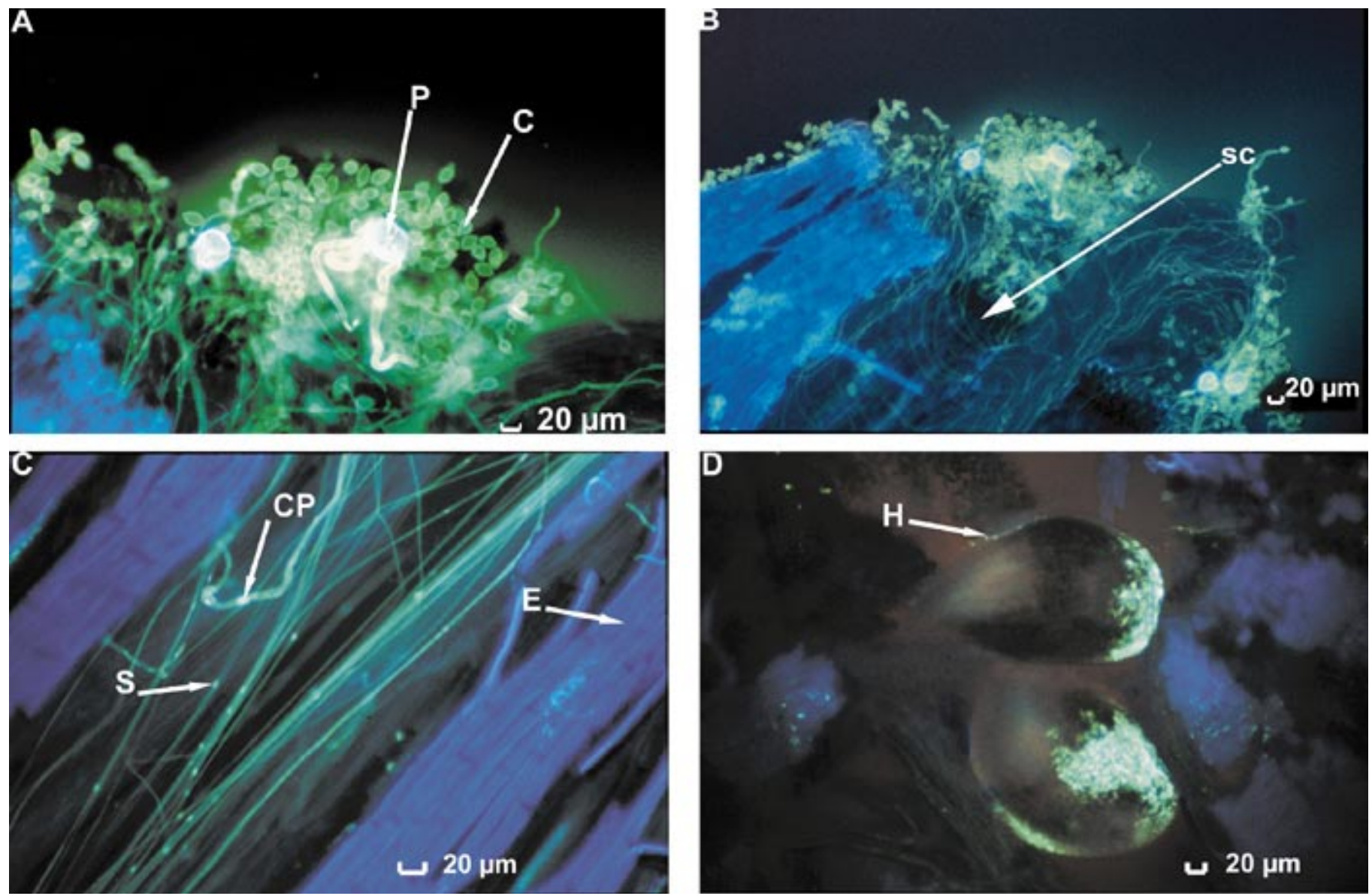

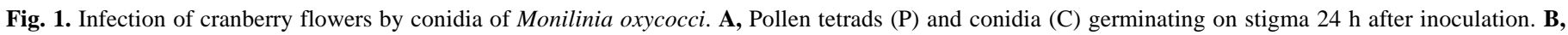

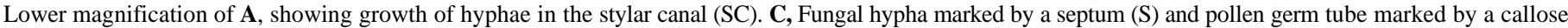
plug (CP) growing through the stylar canal. Epidermis of the style (E) appears blue. D, Fungal hypha $(\mathrm{H})$ growing on surface of an ovule $72 \mathrm{~h}$ after inoculation. 
two-tailed test because some of the counts were too low to justify a $\chi^{2}$ approximation.

The cultivar screening data was analyzed using PROC GLM. Data were transformed by the arcsine-square root calculation to correct nonnormality in residuals. Preliminary analyses of variance for the two repetitions of the experiment showed similar trends in $P$ values of the $F$ statistic for block, isolate, cultivar, and isolate-cultivar effects. Moreover, the repetition-treatment interaction was not significant. Therefore, the two experiments were combined for further analysis. The full data set, including noninoculated control flowers, was analyzed to confirm that inoculated flowers had a higher incidence of cottonball than noninoculated flowers, despite contamination of control flowers by researchers or insects. Control flower data were excluded in a final analysis in order to assess differences in cottonball incidence among cultivars and to avoid unequal variances between the inoculated and noninoculated treatments.

\section{RESULTS}

Floral infection. Conidia and pollen were routinely observed germinating on and penetrating stigmata (Fig. 1A and B). Fungal germ tubes were $\approx 2.5 \mu \mathrm{m}$ wide and marked by narrow, lightly fluorescent septa at regularly spaced intervals; pollen germ tubes were 10 to $20 \mu \mathrm{m}$ wide and marked by broad, brightly fluorescent callose deposits at irregularly spaced intervals (Fig. 1C). Both fungal and pollen germ tubes grew through the stylar canal (Fig. 1B and $\mathrm{C}$ ), entered the ovary by $72 \mathrm{~h}$ after inoculation and pollination, and made direct contact with ovules and nucellar tissue (Fig. 1D). In the absence of pollen, conidia germinated on the stigma and germ tubes grew through the stylar canal. No specialized infection structures, such as appressoria or penetration pegs, were observed, nor did the fungus enter through stomata on petals, pedicels, or ovaries. Germinated conidia were observed on anthers, nectaries, and petals, but not styles. The stigma was the only flower part penetrated by $M$. oxycocci. No differences in spore germination and fungal growth on different cultivars were noted during microscopic analysis.

Cottonball incidence was greater in trial 2 than in trial 1 (Table 1). In both trials and for both cultivars, cottonball incidence was significantly greater when stigmata were inoculated compared to the noninoculated controls (Table 1). A low incidence of cottonball occurred when flower parts other than the stigma were inoculated, but differed significantly from the noninoculated controls only for

TABLE 1. Cottonball incidence after inoculation of cranberry flower parts with conidia of Monilinia oxycocci $i^{\mathrm{a}}$

\begin{tabular}{llcc}
\hline \multirow{2}{*}{$\begin{array}{llc}\text { Flower part } \\
\text { inoculated }\end{array}$} & Cultivar & Trial 1 & Trial 2 \\
\cline { 3 - 4 } Anther & Ben Lear & 0 & 2 \\
& Pilgrim & 0 & 3 \\
Nectary & Ben Lear & 0 & 1 \\
& Pilgrim & 0 & 6 \\
Petal & Ben Lear & 0 & 3 \\
& Pilgrim & 0 & 2 \\
Stigma & Ben Lear & $16^{*}$ & $66^{* * *}$ \\
\multirow{2}{*}{ Style } & Pilgrim & $11^{*}$ & $82^{* * * *}$ \\
& Ben Lear & 0 & 3 \\
None (control) & Pilgrim & 5 & $14^{*}$ \\
& Ben Lear & 2 & 1 \\
& Pilgrim & 0 & 1
\end{tabular}

a Agar plugs covered with sporulating hyphae of various isolates of $M$. oxycocci were rubbed against flower parts. To ensure a high rate of fruit set, stigmata were hand-pollinated at the time inoculum was applied and 24 to $36 \mathrm{~h}$ later. Control flowers were pollinated but not inoculated.

${ }^{\mathrm{b}}$ Fruit were allowed to develop for $\approx 30$ days, after which cottonball incidence was determined by cutting fruit transversely and observing the presence or absence of white mycelia in the locules. Data were analyzed using Fisher's exact two-tailed test for differences in cottonball incidence between the noninoculated controls and each of the flower parts. * and *** indicate significance at $P<0.05$ and 0.001 , respectively. cv. Pilgrim styles in trial 2 (Table 1). Cottonball incidence did not differ significantly between cvs. Ben Lear and Pilgrim in either trial $1(P=0.782)$ or trial $2(P=0.135)$.

Cultivar screening. Cottonball incidence did not differ significantly among cultivars (Table 2). Cottonball incidence was significantly greater in inoculated than noninoculated flowers $(P<$ $0.001)$ and for isolate 593 than isolate $591(P=0.027)$. The isolate-cultivar interaction was not significant $(P=0.484)$.

\section{DISCUSSION}

Knowledge of the floral infection process is key to optimizing control of cottonball. From microscopic observations (Fig. 1) and cottonball incidence following inoculation of different flower parts (Table 1), we conclude that the cranberry stigma is the sole floral infection court for conidia of $M$. oxycocci. Infection of cranberry flowers by conidia of $M$. oxycocci is analogous to infection of highbush and lowbush blueberry by conidia of M. vaccinii-corymbosi: conidia germinate on the stigma, germ tubes enter the stylar canal without specialized infection structures, and hyphae grow through the style to the ovary (Fig. 1) $(1,12,14)$. However, we observed hyphae of $M$. oxycocci in the ovary of cranberry by $72 \mathrm{~h}$ after inoculation, whereas hyphae of $M$. vaccinii-corymbosi were not observed in the ovary of highbush or lowbush blueberry until 7 days after inoculation $(12,14)$.

Two aspects of the flower-part inoculation experiment evoke discussion. First, disease incidence in trial 2 was much greater than in trial 1 (Table 1). We believe this was because, in trial 1 , inoculum was stored in a refrigerator for up to $\approx 15$ days; frequently, water condensed on the plates and inoculum. In trial 2, however, fresh inoculum was always available and never stored in a refrigerator before use; the conidia remained dry and readily adhered to flowers parts during inoculation. A second point concerns the low level of cottonball following inoculation of parts other than the stigma and in noninoculated control flowers (Table 1). In preliminary tests, inoculated and noninoculated control flowers were physically separated by several meters in the greenhouse, and control flowers never developed cottonball. For the experiments reported, however, controls were randomized among the inoculated plants. Thus, the low level of cottonball that resulted following inoculation of anthers, nectaries, petal, and styles and in noninoculated control flowers can probably be attributed to contamination of stigmata by researchers during experimental manipulations or by insects present in the greenhouse. Inoculating styles without touching stigmata was especially difficult for cv. Pilgrim flowers, which have relatively short styles.

The rapid ingress of $M$. oxycocci through the stigma and stylar canal of cranberry suggests that, for a fungicide to be effective, it

TABLE 2. Incidence of cottonball secondary infection after pollination and inoculation of cranberry stigmata with two isolates of Monilinia oxycocci $i^{\mathrm{a}}$

\begin{tabular}{lcc}
\hline Cultivar & No. of flowers inoculated & Cottonball incidence $(\%)^{\mathrm{b}}$ \\
\hline Ben Lear & 209 & 31 \\
Pilgrim & 535 & 28 \\
Searles & 552 & 25 \\
Stevens & 530 & 38 \\
\hline
\end{tabular}

a Agar plugs covered with sporulating hyphae of Monilinia oxycocci isolates 591 and 593 were rubbed against stigmata. Flowers were pollinated and inoculated 20 to $30 \mathrm{~h}$ after the first pollination and inoculation. Control flowers were pollinated but not inoculated. Data from two experiments were combined; no cv. Ben Lear flowers were available for the second experiment.

${ }^{\mathrm{b}}$ Fruit were allowed to develop for $\approx 30$ days, after which cottonball incidence was determined by cutting fruit transversely and observing the presence or absence of white mycelia in the locules. Cottonball incidence was defined as the number of infected berries per total number of berries multiplied by 100. Data were transformed by the arcsine-square root calculation prior to analysis of variance, but actual means are shown. Cultivar effect was not significant $(P=0.558)$. 
must be active during or within a few days of infection. Although the systemic movement and postinfection activity of propiconazole in cranberry flowers have not been determined, DMI fungicides generally are transported acropetally in the apoplast and are active in inhibiting hyphal elongation for 2 to 4 days after infection $(15,16)$. If fungicide uptake occurs primarily through the style, then the after-infection activity of propiconazole would be especially valuable in inhibiting hyphal growth in the stylar canal, but acropetal transport would be ineffective in preventing fungal colonization of the ovary. Alternatively, if uptake occurs through the pedicel or ovary, then acropetal transport would be critical in delivering the fungicide to the site of fungal colonization. In either case, the importance of rapid hyphal elongation and fungal colonization, and the apparent absence of specialized infection structures, should be taken into account as new chemistries are considered for controlling infection of cranberry flowers by $M$. oxycocci.

Previously, floral infection of rosaceous hosts by Botrytis cinerea was investigated to improve the understanding of gray mold disease and ultimately to facilitate selection of disease-resistant lines. Williamson and McNicol (17) reported that conidial germination on stigmata and hyphal colonization of styles and ovaries by $B$. cinerea varied on raspberry cultivars. Bristow et al. (2) reported that hyphal colonization of styles but not conidial germination on stigmata by $B$. cinerea was dependent on strawberry cultivar. In the current study, floral infection was observed most thoroughly on cvs. Ben Lear and Pilgrim, and there were no obvious microscopic differences in the response of these two cultivars to $M$. oxycocci. However, these two cultivars also did not differ in susceptibility to cottonball in either the infection court experiments or the cultivar screening (Table 2). If, in the future, cultivars are identified that differ substantially in susceptibility to cottonball, the squash-mount method described in this study would be useful for determining whether the early infection events on the stigma and in the stylar canal differ among cultivars.

Our cultivar-screening study has made at least two practical contributions to the long-term management of cottonball. First, our data indicate that none of the preferred cranberry cultivars in Wisconsin is inherently resistant to cottonball. In particular, cv. Stevens, which in recent years has accounted for nearly all new and renovated plantings in Wisconsin, is as susceptible to secondary infection as other common cultivars. Although cottonball has been reported in cv. Stevens plantings at several sites, this cultivar is reputed to be relatively resistant. This may be because much of the cv. Stevens acreage has been planted during the past 5 years and cottonball disease pressure has not yet accumulated. Second, we have established a method for evaluating conventional or transgenic germ plasm in the future. A total of 139 cranberry cultivars have been described, and all but 7 of these were selected from native populations (4). Thus, despite the susceptibility of currently popular cultivars and the reported lack of genetic variability in native populations (3), there is a significant resource of native germ plasm that could be exploited for the development of cottonballresistant lines. Ultimately, planting resistant cultivars would increase the sustainability of cottonball management and safety for consumers and the environment.

Our experiments were limited to testing susceptibility at one stage during the cottonball disease cycle (i.e., secondary infection). Cottonball susceptibility in the field is likely determined by genetic interactions of $M$. oxycocci with cranberry during both primary and secondary infection stages, temporal overlap of conidia production and bloom, and environmental influences such as temperature and moisture. Resistance of blueberry cultivars to mummy berry has sometimes been attributed to a combination of biochemical factors and "disease escape," because cultivars with relatively late shoot elongation presumably avoid exposure of susceptible tissue during peak ascospore discharge $(5,6)$. The initiation and rate of apothecium development in a population of $M$. vaccinii-corymbosi occurred 8 to 15 days earlier in an early maturing cultivar than in a late maturing cultivar of highbush blueberry, providing evidence of adaptation of pathogen populations to host phenology (10). If an analogous situation holds with $M$. oxycocci on cranberry, then older plantings might appear more susceptible to cottonball not only because the pathogen population has had more time to amass, but also because the pathogen population has had more time to adapt to its host.

\section{ACKNOWLEDGMENTS}

This study was supported by Wisconsin Cranberry Board Inc., Ocean Spray Cranberries Inc., University of Wisconsin's University-Industry Relations Industrial and Economic Development Research Program, and USDA Hatch (Project 3921). We thank R. Caldwell, M. Kennelly, and A. Dudding for technical support, M. Clayton for statistical advice, J. Helgesen and G. Stanosz for presubmission review, and J. Habelman and G. Gottschalk for cranberry plants.

\section{LITERATURE CITED}

1. Batra, L. R. 1983. Monilinia vaccinii-corymbosi (Sclerotiniaceae): Its biology on blueberry and comparison with related species. Mycologia 75:131-152.

2. Bristow, P. R., McNicol, R. J., and Williamson, B. 1986. Infection of strawberry flowers by Botrytis cinerea and its relevance to gray mould development. Ann. Appl. Biol. 109:545-554.

3. Bruederle, L. P., Hugan, M. S., Dignan, J. M., and Vorsa, N. 1996. Genetic variation in natural populations of the large cranberry Vaccinium macrocarpon Ait. (Ericaceae). Bull. Torrey Bot. Club. 123:41-47.

4. Eck, P. 1990. Plant improvement. Pages 56-80 in: The American Cranberry. Rutgers University Press, New Brunswick, NJ.

5. Ehlenfeldt, M. K., Stretch, A. W., and Brewster, V. 1996. Genetic and morphological factors influence mummy berry blight resistance in highbush blueberry cultivars. HortScience 31:252-254.

6. Ehlenfeldt, M. K., Stretch, A. W., and Lehman, J. 1997. Shoot length affects susceptibility to mummy berry blight within highbush blueberry cultivars. HortScience 32:884-887.

7. Jeffers, S. N. 1991. Managing cranberry cottonball caused by Monilinia oxycocci with fungicides. Plant Dis. 75:502-506.

8. Jeffers, S. N., and Sanderson, P. G. 1995. Cottonball. Pages 33-35 in: Compendium of Blueberry and Cranberry Diseases. F. L. Caruso and D. C. Ramsdell, eds. The American Phytopathological Society, St. Paul, MN.

9. Johnson, T. E., and McManus, P. S. 1998. Inhibition of conidial germination and radial growth of Monilinia oxycocci by bacteria isolated from a cranberry marsh. (Abstr.) Phytopathology 88(suppl.):S45.

10. Lehman, J. S., and Oudemans, P. V. 1997. Phenology of apothecium production in populations of Monilinia vaccinii-corymbosi from earlyand late-maturing blueberry cultivars. Phytopathology 87:218-223.

11. McManus, P. S., Best, V. M., Voland, R. P., and Leininger, B. L. 1999. Sensitivity of Monilinia oxycocci to fenbuconazole and propiconazole in vitro and control of cranberry cottonball in the field. Plant Dis. 83:445450 .

12. Millholland, R. D. 1977. Sclerotium germination and histopathology of Monilinia vaccinii-corymbosi on high bush blueberry. Phytopathology 67:848-854.

13. Novy, R. G., Kobak, C., Goffreda, J., and Vorsa, N. 1994. RAPDs identify varietal misclassification and regional divergence in cranberry (Vaccinium macrocarpon (Ait.) Pursh). Theor. Appl. Genet. 88:1004-1010.

14. Shinners, T. C., and Olson, A. R. 1996. The gynoecial infection pathway of Monilinia vaccinii-corymbosi in lowbush blueberry. Can. J. Plant Sci. 76:493-497.

15. Siegel, M. R. 1981. Sterol-inhibiting fungicides: Effects on sterol biosynthesis and sites of action. Plant Dis. 65:986-989.

16. Szkolnik, M. 1981. Physical modes of action of sterol-inhibiting fungicides against apple diseases. Plant Dis. 65:981-985.

17. Williamson, B., and McNicol, R. J. 1986. Pathways of infection of flowers and fruits of red raspberry by Botrytis cinerea. Acta Hortic. 183:137141. 